\title{
Mouthwash Use in General Population: Results from Adult Dental Health Survey in Grampian, Scotland
}

\author{
Tatiana V. Macfarlane ${ }^{1}$, Michal M. Kawecki ${ }^{2}$, Claudia Cunningham ${ }^{1,3}$, Iain Bovaird ${ }^{1,3}$, Rochelle \\ Morgan $^{3}$, Kirstin Rhodes ${ }^{3}$, Ray Watkins ${ }^{3}$ \\ ${ }^{1}$ School of Medicine and Dentistry, University of Aberdeen, Aberdeen, United Kingdom \\ ${ }^{2}$ School of Medical Sciences, University of Aberdeen, Aberdeen, United Kingdom \\ ${ }^{3}$ NHS Grampian, Aberdeen, United Kingdom
}

\author{
Corresponding Author: \\ Tatiana V. Macfarlane \\ Aberdeen Pain Research Collaboration, Division of Applied Medicine \\ School of Medicine and Dentistry, University of Aberdeen \\ Polwarth Building, Foresterhill, Aberdeen AB25 2ZD \\ United Kingdom \\ Phone: +44 1224551585 \\ Fax: +44 1224554761 \\ E-mail tatiana.macfarlane@abdn.ac.uk
}

\begin{abstract}
Objectives: The purpose of this study was to determine the pattern of mouthwash use and to investigate the associated factors in general population.

Material and Methods: An Adult Dental Health Survey was conducted on 3,022 residents of Grampian region of Scotland (adjusted participation rate 58.2\%). Participants received a questionnaire consisting of questions on oral health and behavioural factors.

Results: The majority of participants (38.1\%) have never used mouthwash, $17.5 \%$ used mouthwash less than once a month, $19.4 \%$ used mouthwash once every few days and $25.1 \%$ used mouthwash daily.

Prevalence of use decreased with age $(\mathrm{P}<0.001)$. Woman were more likely to use mouthwash than men $(\mathrm{P}=0.004)$. Mouthwash use decreased with decrease in the level of deprivation $(\mathrm{P}<0.001)$. Never-smokers were less likely to use mouthwash $(40.3 \%)$ compared to smokers $(53.1 \%)$ or those who stopped smoking $(46.5 \%)(\mathrm{P}<0.001)$. Mouthwash was used by smaller proportion of people drinking alcohol on daily basis $(36.6 \%)$, than by abstainers $(42.2 \%)(\mathrm{P}=0.012)$.

There was a positive relationship between flossing or brushing pattern and mouthwash use $(\mathrm{P}<0.001)$. There was statistically significant relationship between mouthwash use and reasons for the last dental visit $(\mathrm{P}=0.009)$.

When compared to healthy individuals, mouthwash was used by higher proportion of people reporting that they had gum disease $(\mathrm{P}=0.001)$, ulcers $(\mathrm{P}=0.001)$, oral infections or swelling $(\mathrm{P}=0.002)$ or other problems $(\mathrm{P}=0.025)$.

Conclusions: Mouthwash use in general population is associated with socio-demographic, health and behavioural factors.
\end{abstract}

Keywords: mouthwashes; oral hygiene; dental plaque; epidemiology; dental health survey; population groups.

Accepted for publication: 22 October 2010

To cite this article:

Macfarlane TV, Kawecki MM, Cunningham C, Bovaird I, Morgan R, Rhodes K, Watkins R. Mouthwash Use in General Population: Results from Adult Dental Health Survey in Grampian, Scotland.

J Oral Maxillofac Res 2010 (Oct-Dec);1(4):e2

URL: http://www.ejomr.org/JOMR/archives/2010/4/e2/v1n4e2ht.pdf

doi: 10.5037/jomr.2010.1402 


\section{INTRODUCTION}

Inadequate oral hygiene has an important role in aetiology of plaque growth. Plaque constitutes the primary factor responsible for dental diseases, ranging from caries to gum disease (gingivitis and periodontitis). Daily tooth brushing is the main mechanical method of plaque removal and therefore reduces the risk of development of dental diseases [1]. A toothbrush (powered or manual) cannot access dental surfaces underneath the contact zone between teeth. Interdental brush or floss is recommended to supplement toothbrushing to remove the accumulated material from between teeth more efficiently [2]. The interdental area is one of the most frequent sites of plaque accumulation, caries development, and the beginning of periodontitis. The standard of oral hygiene is particularly affected in patients who do not possess manual dexterity or motivation for mechanical plaque disruption [3]. Mouthwashes can be valuable aids in reduction of the supragingival plaque levels and prevention of gingivitis.

Mouthwashes have little penetrating abilities to the subgingival environment $[\underline{3}, 4]$. They should be treated as an adjunct to the primary mechanical methods of cleaning, but not regarded as their substitute [3] . Mouthwash effectiveness relies on the patient's ability to rinse properly. The products are therefore not suitable for utilization by patients who cannot understand simple instructions or who are physically unable to rinse. In these types of patients directly applied anti-plaque agents may be more applicable [4].

Before use of a particular mouthwash, the following factors should be taken into account: person's capability of delivering good oral hygiene (e.g. brushing, flossing), the state of their periodontal health, teeth and oral mucosa as well as the mechanism of mouthwash activity with its potential side effects [5].

In addition to use for oral hygiene, mouthwashes have been utilized for many pathological conditions, for instance gum disorders [4]. They are, similar to toothpaste, formulated to exert additional diverse, beneficial effects such as reduction of dental sensitivity or decrease of halitosis by the inclusion of specific combination of active ingredients. Ethanol is utilized in many mouthwashes and functions as solvent and preservative [4]. It possesses wide antimicrobial activity. It has been suggested that use of alcoholcontaining mouthwash may increase risk of oral cancer [6]. However critical review of published data showed that this link was not supported by epidemiological evidence [7]. It has been suggested that mouthwash use might be more prevalent in people with oral inflammatory conditions and pre-cancerous lesions, and also that confounding due to underreported exposure to alcohol and tobacco could result in a spuriously elevated odds ratio for mouthwash use [8]. Few studies reported factors associated with mouthwash use $[\underline{9}, \underline{10}]$.

The purpose of this study was to determine the prevalence of mouthwash use and to investigate the associated factors in general population.

\section{MATERIAL AND METHODS}

The Grampian Adult Dental Health Survey was conducted in the Grampian region of Scotland between October 2009 and January 2010 and aimed to evaluate current state of oral health, access to dental care and a range of related behaviours. The use of human subjects in this study has been approved by the Grampian National Health Service (NHS) Board. Age, gender and area stratified random sample of 6,000 people aged 25 years and over was selected from the Community Health Index (CHI) database (http://www.shsc.scot.nhs.uk/shsc/default.asp?p=108). The CHI database contains details of all Scottish residents registered with a General Medical Practitioner. NHS Grampian had recently undertaken a youth and young people lifestyle survey (http://www.hi-netgrampian.org), and therefore 16 - 24 year olds were not sampled. Each selected individual received a postal questionnaire. The questionnaire consisted of 51 questions on socio-demographic characteristics (age, gender, education), oral health, health related behaviours and dental services utilisation. A follow-up of non-responders was performed initially with a reminder postcard, a further questionnaire and finally where necessary, a short questionnaire (10 questions). Information was collected on a range of socio-demographic characteristics (age, gender, education, social class), oral health and health related behaviours. The short questionnaire consisted of 10 key questions on age, gender, dental services utilisation and number of teeth. Deprivation was measured using the Scottish Index of Multiple Deprivation (SIMD) (http://www.scotland.gov.uk/Topics/Statistics/SIMD/) which was obtained from the participants' postcodes. The SIMD gives a relative measure of deprivation by providing a relative ranking, with most deprived ranked as " 1 ".

The specific question that was asked about mouthwash use was as follows: "How often do you rinse with a mouthwash?". The options for response were: daily; once every few days; less than once a month or never. For the purpose of the data analysis, mouthwash users were defined as using every day or once every few days and 
non-users as using mouthwash less than once a month or never.

\section{Statistical analysis}

Initial statistical analysis consisted of descriptive tables (tabulation by age, gender and area). Chi-square test was used for univariate analysis in order to compare between users and non-users. For multivariate analysis, Cox regression [11] was used to estimate relative risk adjusted for potential confounders. The magnitude of association between a factor and mouthwash use was described by the Relative Risk (RR). This is a more meaningful effect measure for representative crosssectional studies than the Odds Ratio [12]. The RR was considered significantly different from " 1 " if the $95 \%$ confidence interval did not include " 1 ". All factors were grouped as following: socio-economic and behavioural factors; behavioural factor related to oral health; and heath factors. The subset of variables that best predict mouthwash use, was determined using backward stepwise procedure. Significance level was set to 0.05. All analysis was done using PASW Statistics 18 (Release 18.0.2, April 2, 2010, http://www.spss.com/).

\section{RESULTS}

A total 3,022 full and 331 short questionnaires were returned. Of the remainder, 250 subjects were assumed not to have received the questionnaire, either because notification was received from the occupants or post office that the subject had moved $(n=205)$, they were severely disabled/terminally ill $(\mathrm{n}=2)$ or had died $(\mathrm{n}=30)$. This resulted in an adjusted participation rate of $58.2 \%$. Participation rate was the highest in the age group 55 - 64 (68.5\%) and the lowest in $25-34(47.3 \%)$. Women were more likely to reply than men $(61.9 \%$ and $54.6 \%$, respectively). The lowest participation rate was among the most deprived participant (SIMD Quintile 1,

Table 1. Relationship between socio-demographic and behavioural factors and mouthwash use

\begin{tabular}{|c|c|c|c|}
\hline Factor & $\begin{array}{c}\text { Number in } \\
\text { group }\end{array}$ & $\begin{array}{c}\text { Mouthwash } \\
\text { user (\%) }{ }^{\mathrm{a}}\end{array}$ & $\begin{array}{l}\mathrm{X}^{2} \text { test } \\
\text { P-value }\end{array}$ \\
\hline \multicolumn{4}{|l|}{ Age (years) } \\
\hline $25-34$ & 450 & 56.0 & \multirow{6}{*}{$<0.001$} \\
\hline $35-44$ & 585 & 48.9 & \\
\hline $45-54$ & 432 & 42.6 & \\
\hline $55-64$ & 473 & 39.3 & \\
\hline $65-74$ & 396 & 36.4 & \\
\hline $75+$ & 239 & 38.9 & \\
\hline \multicolumn{4}{|l|}{ Gender } \\
\hline Female & 1348 & 47.2 & \multirow{2}{*}{0.004} \\
\hline Male & 1227 & 41.5 & \\
\hline \multicolumn{4}{|l|}{ Scottish Index of Multiple Deprivation (SIMD Quintile) } \\
\hline 1 (most deprived) & 89 & 50.6 & \multirow{5}{*}{$<0.001$} \\
\hline 2 & 265 & 53.2 & \\
\hline 3 & 654 & 48.6 & \\
\hline 4 & 850 & 41.1 & \\
\hline 5 & 717 & 40.7 & \\
\hline \multicolumn{4}{|l|}{ Education level } \\
\hline Secondary school & 1053 & 44.8 & \multirow{4}{*}{$<0.001$} \\
\hline Technical College & 712 & 50.1 & \\
\hline University/Postgraduate & 741 & 39.0 & \\
\hline Other & 48 & 33.3 & \\
\hline \multicolumn{4}{|l|}{ Smoking } \\
\hline Currently smoking or have stopped within the last 12 months & 471 & 53.1 & \multirow{3}{*}{$<0.001$} \\
\hline Stopped smoking over 12 months ago & 626 & 46.5 & \\
\hline Never smoked & 1364 & 40.3 & \\
\hline \multicolumn{4}{|l|}{ Alcohol consumption } \\
\hline Almost everyday & 295 & 36.6 & \multirow{4}{*}{0.012} \\
\hline Once or twice a week & 946 & 46.5 & \\
\hline Less than once a week & 876 & 46.2 & \\
\hline Do not drink & 396 & 42.2 & \\
\hline
\end{tabular}

aUser: every day or once every few days; non-user: less than once a month or never. 
$44.6 \%)$ and the highest in more affluent $(60.7 \%$ in quintile 4 and $60.4 \%$ in quintile 5 ).

The question on mouthwash use was answered by 2,575 participants. A large proportion of adults (38.1\%) had never used mouthwash, $17.5 \%$ used mouthwash occasionally - less than once a month, $19.4 \%$ used mouthwash once every few days and $25.1 \%$ used mouthwash daily.

The relationship between socio-demographic and behavioural factors is presented in Table 1. Prevalence of use decreased with age from $56 \%$ in $25-34$ age group to $36.4 \%$ in $65-74$ age group $(\mathrm{P}<0.001)$. Woman were more likely to use mouthwash than men $(47.2 \%$ and $41.5 \%$, respectively $(\mathrm{P}=0.004)$. Mouthwash use decreased with decrease in the level of deprivation: people living in most deprived areas were more likely to use mouthwash than participants from affluent areas (50.6\% and 40.7\%, respectively) ( $\mathrm{P}<0.001)$. Neversmokers were less likely to use mouthwash $(40.3 \%)$ compared to smokers $(53.1 \%)$ or those who stopped smoking $(46.5 \%)(\mathrm{P}<0.001)$. Mouthwash was used by a smaller proportion of people drinking alcohol on a daily basis $(36.6 \%)$, than by abstainers $(42.2 \%)(\mathrm{P}=0.012)$. Although the relationship between education level and mouthwash use was also statistically significant $(\mathrm{P}<0.001)$ and no consistent pattern could be observed. The results obtained supported a positive relationship between flossing and brushing frequency and mouthwash $(\mathrm{P}<0.001)$ (Table 2). The proportion of people who used mouthwash was highest among those flossing daily and brushing two or more times a day (59.9\% and $48.7 \%$ respectively). Mouthwash use was the lowest amongst people who never floss or brush their teeth (37.3\% and $27.8 \%$ respectively). There was no relationship between mouthwash use and type of regular dental care received or time since last check-up. There was statistically significant relationship between mouthwash use and reasons for the last dental visit $(\mathrm{P}=0.009)$.

There was no relationship between self-reported general and dental health, current number of natural teeth, dental decay, possession of a bridge, dental implants, dentures and mouthwash use (Table 3 ). When compared to healthy individuals, mouthwash was used by higher proportion of people recording they suffered from gum disease $(55.7 \%$ vs $43.5 \% ; \mathrm{P}=0.001)$, ulcers $(59.0 \%$ vs $43.7 \% ; \mathrm{P}=0.001)$, oral infections or swelling $(63.2 \%$ vs $44.0 \%, \mathrm{P}=0.002)$ or other oral problems $(51.2 \%$ vs $43.8 \%, \mathrm{P}=0.025)$.

Table 2. Relationship between behavioural factors related to oral health and mouthwash use

\begin{tabular}{|c|c|c|c|}
\hline Factor & $\begin{array}{c}\text { Number in } \\
\text { group }\end{array}$ & $\begin{array}{c}\text { Mouthwash } \\
\text { user (\%) }\end{array}$ & $\begin{array}{l}\mathrm{X}^{2} \text { test } \\
\text { P-value }\end{array}$ \\
\hline \multicolumn{4}{|l|}{ Type of regular dental care received } \\
\hline NHS (State Healthcare) & 1169 & 44.6 & \multirow{3}{*}{0.365} \\
\hline Private & 329 & 48.3 & \\
\hline Unable to get a dentist & 989 & 43.9 & \\
\hline \multicolumn{4}{|l|}{ Time since last dental check-up } \\
\hline Less than a year & 1945 & 43.5 & \multirow{5}{*}{0.128} \\
\hline $1-2$ years & 241 & 44.8 & \\
\hline $2-5$ years & 133 & 54.9 & \\
\hline $5-10$ years & 132 & 47.7 & \\
\hline Have not visited a dentist for over 10 years & 111 & 43.2 & \\
\hline \multicolumn{4}{|l|}{ Reasons for the last dental visit } \\
\hline Emergency treatment needed for teeth or gums & 372 & 50.3 & \multirow{5}{*}{0.009} \\
\hline Non-urgent treatment for teeth or gums & 373 & 43.7 & \\
\hline Dental check-up & 1610 & 42.4 & \\
\hline Can't remember & 96 & 52.1 & \\
\hline Other & 105 & 53.3 & \\
\hline \multicolumn{4}{|l|}{ Flossing frequency } \\
\hline Daily & 339 & 59.9 & \multirow{4}{*}{$<0.001$} \\
\hline Once every few days & 617 & 51.9 & \\
\hline Less than once a month & 515 & 39.6 & \\
\hline Never & 1083 & 37.3 & \\
\hline \multicolumn{4}{|l|}{ Tooth brushing frequency } \\
\hline Twice or more a day & 1726 & 48.7 & \multirow{4}{*}{$<0.001$} \\
\hline Once a day & 742 & 36.8 & \\
\hline Less than daily & 86 & 31.4 & \\
\hline Never & 18 & 27.8 & \\
\hline
\end{tabular}

aUser: every day or once every few days; non-user: less than once a month or never. 
Table 3. Relationship between health factors and mouthwash use

\begin{tabular}{|c|c|c|c|}
\hline Factor & $\begin{array}{l}\text { Number in } \\
\text { group }\end{array}$ & $\begin{array}{c}\text { Mouthwash } \\
\text { user }(\%)^{\mathrm{a}}\end{array}$ & $\begin{array}{l}\mathrm{X}^{2} \text { test } \\
\mathrm{P} \text {-value }\end{array}$ \\
\hline \multicolumn{4}{|l|}{ General health } \\
\hline Excellent & 622 & 42.9 & \multirow{4}{*}{0.735} \\
\hline Good & 1498 & 45.5 & \\
\hline Fair & 343 & 44.0 & \\
\hline Poor & 59 & 44.1 & \\
\hline \multicolumn{4}{|l|}{ Dental health } \\
\hline Excellent & 299 & 40.5 & \multirow{4}{*}{0.098} \\
\hline Good & 1365 & 44.3 & \\
\hline Fair & 659 & 45.4 & \\
\hline Poor & 191 & 51.8 & \\
\hline \multicolumn{4}{|c|}{ Current number of natural teeth } \\
\hline Fewer than 10 & 217 & 43.3 & \multirow{3}{*}{0.628} \\
\hline Between 10 and 19 & 512 & 46.3 & \\
\hline 20 or more & 1825 & 44.1 & \\
\hline \multicolumn{4}{|l|}{ Dental decay } \\
\hline No & 2145 & 43.8 & \multirow{2}{*}{0.116} \\
\hline Yes & 430 & 47.9 & \\
\hline \multicolumn{4}{|l|}{ Gum disease } \\
\hline No & 2365 & 43.5 & \multirow{2}{*}{0.001} \\
\hline Yes & 210 & 55.7 & \\
\hline \multicolumn{4}{|l|}{ Ulcers } \\
\hline No & 2453 & 43.7 & \multirow{2}{*}{0.001} \\
\hline Yes & 122 & 59.0 & \\
\hline \multicolumn{4}{|l|}{ White or red patches } \\
\hline No & 2505 & 44.2 & \multirow{2}{*}{0.094} \\
\hline Yes & 70 & 54.3 & \\
\hline \multicolumn{4}{|c|}{ Oral infection or swelling } \\
\hline No & 2507 & 44.0 & \multirow{2}{*}{0.002} \\
\hline Yes & 68 & 63.2 & \\
\hline \multicolumn{4}{|l|}{ Other problems } \\
\hline No & 2331 & 43.8 & \multirow{2}{*}{0.025} \\
\hline Yes & 244 & 51.2 & \\
\hline \multicolumn{4}{|l|}{ Possession of bridge } \\
\hline No & 2390 & 44.2 & \multirow{2}{*}{0.378} \\
\hline Yes & 185 & 47.6 & \\
\hline \multicolumn{4}{|c|}{ Possession of dental implants } \\
\hline No & 2438 & 44.6 & \multirow{2}{*}{0.489} \\
\hline Yes & 137 & 41.6 & \\
\hline \multicolumn{4}{|l|}{ Possession of dentures } \\
\hline No & 1945 & 44.3 & \multirow{2}{*}{0.792} \\
\hline Yes & 630 & 44.9 & \\
\hline
\end{tabular}

${ }^{a}$ User: every day or once every few days; non-user: less than once a month or never.

Multivariate model for group one, apart from age and gender, included education and smoking. Multivariate model for group two included reason for the last dental visit, toothbrush frequency and flossing frequency.

Multivariate model for the third group included gum disease and ulcers. The final model for all variables included seven variables: age, education, smoking, reason for the last dental visit, toothbrushing, flossing and gum disease (Table 4).

Table 5 shows how well the factors entered into the final model described the prevalence of mouthwash use.
The proportion of users increased with the increase in number of factors reported to be positive, with $93.8 \%$ of those reporting exposure to all six factors using mouthwash.

\section{DISCUSSION}

The findings indicate that pattern of mouthwash use is associated with demographic, socio-economic, behavioural and health-related factors in a large 
Table 4. Multivariate model for mouthwash use

\begin{tabular}{lr}
\hline \multicolumn{1}{c}{ Variable } & $\begin{array}{r}\text { RR (95\% CI) of } \\
\text { mouthwash use }\end{array}$ \\
\hline Age (years) & 1.00 \\
\hline $75+$ & $0.91(0.68,1.22)$ \\
$65-74$ & $0.95(0.72,1.25)$ \\
$55-64$ & $1.06(0.81,1.40)$ \\
$45-54$ & $1.20(0.93,1.56)$ \\
$35-44$ & $1.44(1.11,1.88)$ \\
$25-34$ & \\
\hline Education level & 1.00 \\
\hline University/Postgraduate/Other & $1.27(1.10,1.46)$ \\
Secondary school or Technical College & 1.00 \\
\hline Smoking & $1.17(1.01,1.36)$ \\
\hline Never smoked & $1.22(1.05,1.43)$ \\
\hline Stopped smoking over 12 months ago & \\
Currently smoking or have stopped within the last 12 months & 1.00 \\
\hline Reasons for the last dental visit & $1.23(1.07,1.41)$ \\
\hline Non-urgent treatment for teeth or gums or Dental check-up & \\
Emergency treatment needed for teeth or gums, can't remember or other & 1.00 \\
\hline Tooth brushing frequency & $1.21(0.99,1.48)$ \\
\hline Never or less than daily & $1.53(1.06,2.22)$ \\
\hline Once a day & $1.55(1.31,1.84)$ \\
\hline Twice or more a day & 1.00 \\
\hline Flossing frequency & \\
\hline Never or less than once a month & \\
Once every few days & \\
Daily & \\
\hline Gum disease & \\
\hline No & \\
Yes & \\
\hline
\end{tabular}

${ }^{a}$ From Cox regression model; all variable are entered simultaneously.

Table 5. Percentage of mouthwash users by the number of factors in the final model

\begin{tabular}{ccc}
\hline $\begin{array}{c}\text { Number of factors in the final } \\
\text { model }^{\mathbf{a}}\end{array}$ & \% mouthwash users & Total number in group \\
\hline 0 factors & 27.1 & 48 \\
1 factor & 25.7 & 307 \\
2 factors & 33.5 & 744 \\
3 factors & 50.5 & 750 \\
4 factors & 57.4 & 423 \\
5 factors & 71.9 & 128 \\
6 factors & 93.8 & 16 \\
\hline
\end{tabular}

${ }^{\mathrm{a}} \mathrm{Age}$ (25 - 34 years); education (secondary school or technical college); ever smoker; reason for last dental visit (emergency treatment, can't remember or other); tooth brushing frequency (twice or more a day); flossing frequency (once every few days or daily); gum disease. 
population sample of over 2,500 individuals. Personal hygiene is a substantial factor influencing public health [13]. However, health related behaviours are often difficult to change. Investigation of healthrelated behaviours is important to improve preventive strategies [14].

The results showed the decline of mouthwash use with age. This might be associated with decrease in number of natural teeth which an individual possesses. However, the use of mouthwash in people above 74 years old maybe related to increasing difficulty in cleaning teeth by other means due to physical disability. The more common use of mouthwash among females (47.2\%) than males $(41.5 \%)$ reported in the current study is in agreement with the results of research by Winn et al. [10]. Tada and Hanada [15] also reported higher prevalence of better oral health behaviours in women. While the current study found statistically significant relationship between use of mouthwash and education level, it is not clear why the highest prevalence of use is among participants with technical college education $(50 \%)$ while prevalence of use among university graduates is much lower $(38.9 \%)$. For example, Neamatollahi and Ebrahimi [16] reported that doctorate and master level students tend to use dental floss more often than bachelor students.

Mouthwashes constitute a common method of eliminating halitosis [17]. According to the present study, smokers used mouthwash more often than nonsmokers. This could be associated with attempts by smokers to reduce oral tobacco odour, halitosis or aftertaste caused by tobacco.

Amongst the group of behavioural factors related to oral health, type of dental care received (Private or National Health Service), date of last dental check-up and reason for the last dental appointment were not related to the pattern of mouthwash use. Frequency of both toothbrushing and flossing were showed to be positively related to the frequency of mouthwash use. Participants concerned about their oral health were more likely to supplement their mechanical removal of dental plaque with a toothbrush or floss by using a mouthwash frequently. Dumitrescu et al. [18] suggest that there is an association between degrees of self-liking, body investment and patterns of dental visits, flossing as well as mouthwash use.

In the group of health-related factors, presence of inflammation, ulcers or gum disease was demonstrated to be related to pattern of mouthwash use. This confirms research by Jones [19] and Farah et al. [ $\underline{5}]$ where such conditions seem to be sufficient stimuli, for affected patients, to initialize mouthwash which possesses antibacterial and antifungal properties. Mouthwash might in these cases constitute an easily accessible (no prescription) remedy to treat a minor oral problem.
Mouthwash use was not related to overall self-rated general health and overall self-rated dental and oral health. Possession of dental bridges, implants, dentures or the presence of white/red patches was not an important factor determining the pattern of mouthwash use. This may contradict expectations that a significant percentage of people with dental bridges or implants would use mouthwash to facilitate cleaning those places inaccessible to toothbrush or floss.

The adjusted participation rate achieved of $58.2 \%$ is relatively low. Every effort was made to increase participation. A press release was published, resulting in radio and newspaper interviews. Non-respondents after the first two weeks were sent a reminder postcard, a further full questionnaire after another two weeks, which was followed by a final short questionnaire in the case of non-response. Previous studies in this geographical area have reported participation rates of $82.3 \%$ [20], $38 \%$ [21] and $25 \%$ [22]. It is important to consider the possible influence of non-participants on the results. This study primarily investigated relationship of various factors with mouthwash use. In order to influence the results, non-responders would need to demonstrate different relationships between these factors and mouthwash use: this seems very unlikely.

This study investigated neither the type of mouthwashes used, direct reasons for use, nor people's beliefs concerning mouth rinsing and therefore it would be a next step for future research.

To summarize, mouthwash use in general population is associated with socio-economic, health and behavioural factors. Although certain factors were demonstrated to be clearly related to the pattern of mouthwash use, the roles of others remain inconclusive and their determination would require further investigation.

\section{CONCLUSIONS}

Mouthwash use in general population is associated with socio-demographic, health and behavioural factors.

\section{ACKNOWLEDGMENTS AND DISCLOSURE STATEMENTS}

We are grateful to the participants for completing the questionnaire. The study was commissioned, developed and funded by NHS Grampian for the purpose of identifying the oral health and related behaviours of the local population. MK was supported by HotStart scholarship. The authors are grateful to V. Angus, F. Chaloner and K. Wilde from the University of Aberdeen for help with sampling and data management.

The authors report no conflict of interest related to this study. 


\section{REFERENCES}

1. Daly GC. Prescribing good oral hygiene for adults. Aust Prescr, 2009 Jun;32: 72-5. [doi: 10.18773/austprescr.2009.036]

2. Kiger RD, Nylund K, Feller RP. A comparison of proximal plaque removal using floss and interdental brushes. J Clin Periodontol. 1991 Oct;18(9):681-4. [Medline: 1960236] [doi: 10.1111/j.1600-051X.1991.tb00109.x]

3. Eley BM. Antibacterial agents in the control of supragingival plaque - a review. Br Dent J. 1999 Mar 27;186(6):286-96. Review. [Medline: 10230103] [doi: 10.1038/sj.bdj.4800090a]

4. Moran JM. Home-use oral hygiene products: mouthrinses. Periodontol 2000. 2008;48:42-53. Review. [Medline: 18715355] [doi: 10.1111/j.1600-0757.2008.00260.x]

5. Farah CS, McIntosh L, McCullough MJ. Mouthwashes. Aust Prescr, 2009 Dec;32:162-4. [doi: 10.18773/austprescr.2009.080]

6. McCullough MJ, Farah CS. The role of alcohol in oral carcinogenesis with particular reference to alcohol-containing mouthwashes. Aust Dent J.2008 Dec;53(4):302-5. Review. [Medline: 19133944] [doi: 10.1111/j.1834-7819.2008.00070.x]

7. La Vecchia C. Mouthwash and oral cancer risk: an update. Oral Oncol. 2009 Mar;45(3):198-200. Epub 2008 Oct 25. Review. [Medline: 18952488] [doi: 10.1016/j.oraloncology.2008.08.012]

8. Shapiro S, Castellana JV, Sprafka JM. Alcohol-containing mouthwashes and oropharyngeal cancer: a spurious association due to underascertainment of confounders? Am J Epidemiol. 1996 Dec 15;144(12):1091-5. Review. [Medline: 8956620] [FREE Full Text]

9. Winn DM, Blot WJ, McLaughlin JK, Austin DF, Greenberg RS, Preston-Martin S, Schoenberg JB, Fraumeni JF Jr. Mouthwash use and oral conditions in the risk of oral and pharyngeal cancer. Cancer Res. 1991 Jun 1;51(11):3044-7. [Medline: 2032242] [doi: 10.1097/00001648-199105000-00006] [FREE Full Text]

10. Winn DM, Diehl SR, Brown LM, Harty LC, Bravo-Otero E, Fraumeni JF Jr, Kleinman DV, Hayes RB. Mouthwash in the etiology of oral cancer in Puerto Rico. Cancer Causes Control. 2001 Jun;12(5):419-29. [Medline: 11545457] [doi: 10.1023/A:1011291807468]

11. Cox DR. Regression models and life tables (with discussion). Journal of the Royal Statistical Society, 34; 187-220. J Roy Statist Soc B. 1972 Mar; 34(2): 187-220. Available from: http://www.jstor.org/stable/2985181

12. Davies HT, Crombie IK, Tavakoli M. When can odds ratios mislead? BMJ. 1998 Mar 28;316(7136):989-91. Review. [Medline: 9550961] [FREE Full Text]

13. Prüss A, Kay D, Fewtrell L, Bartram J. Estimating the burden of disease from water, sanitation, and hygiene at a global level. Environ Health Perspect. 2002 May;110(5):537-42. [Medline: 12003760] [doi: 10.1289/ehp.02110537] [FREE Full Text]

14. Dorri M, Sheiham A, Watt RG. Modelling the factors influencing general and oral hygiene behaviours in adolescents. Int J Paediatr Dent. 2010 Jul;20(4):261-9. [Medline: 20536587] [doi: 10.1111/j.1365-263X.2010.01048.x]

15. Tada A, Hanada N. Sexual differences in oral health behaviour and factors associated with oral health behaviour in Japanese young adults. Public Health. 2004 Mar;118(2):104-9. [Medline: 15037039] [doi: 10.1016/j.puhe.2003.05.007]

16. Neamatollahi H, Ebrahimi M. Oral health behavior and its determinants in a group of Iranian students. Indian J Dent Res. 2010 Jan-Mar;21(1):84-8. [Medline: 20427913] [doi: 10.4103/0970-9290.62820] [FREE Full Text]

17. Fedorowicz Z, Aljufairi H, Nasser M, Outhouse TL, Pedrazzi V. Mouthrinses for the treatment of halitosis. Cochrane Database Syst Rev. 2008 Oct 8;(4):CD006701. Review. [Medline: 18843727] [doi: 10.1002/14651858.CD006701.pub2]

18. Dumitrescu AL, Toma C, Lascu V. Self-liking, self-competence, body investment and perfectionism: associations with oral health status and oral-health-related behaviours. Oral Health Prev Dent. 2009;7(2):191-200. [Medline: 19583045]

19. Jones CG. Chlorhexidine: is it still the gold standard? Periodontol 2000. 1997 Oct;15:55-62. Review. [Medline: 9643233] [doi: 10.1111/j.1600-0757.1997.tb00105.x]

20. Elliott AM, Smith BH, Penny KI, Smith WC, Chambers WA. The epidemiology of chronic pain in the community. Lancet. 1999 Oct 9;354(9186):1248-52. [Medline: 10520633] [doi: 10.1016/S0140-6736(99)03057-3]

21. Vasianovich A, van Teijlingen ER, Reid G, Scott NW. Key health promotion factors among male members of staff at a higher educational institution: a cross-sectional postal survey. BMC Public Health. 2008 Feb 12;8:58. [Medline: 18269744] [doi: 10.1186/1471-2458-8-58] [FREE Full Text]

22. Angus VC, Entwistle VA, Emslie MJ, Walker KA, Andrew JE. The requirement for prior consent to participate on survey response rates: a population-based survey in Grampian. BMC Health Serv Res. 2003 Nov 18;3(1):21. [Medline: 14622444] [doi: 10.1186/1472-6963-3-21] [FREE Full Text] 


\section{To cite this article:}

Macfarlane TV, Kawecki MM, Cunningham C, Bovaird I, Morgan R, Rhodes K, Watkins R. Mouthwash Use in General Population: Results from Adult Dental Health Survey in Grampian, Scotland.

J Oral Maxillofac Res 2010;1(4):e2

URL: http://www.ejomr.org/JOMR/archives/2010/4/e2/v1n4e2ht.pdf

doi: $10.5037 /$ jomr.2010.1402

Copyright (c) Macfarlane TV, Kawecki MM, Cunningham C, Bovaird I, Morgan R, Rhodes K, Watkins R. Accepted for publication in the JOURNAL OF ORAL \& MAXILLOFACIAL RESEARCH (http://www.ejomr.org/), 22 October 2010.

This is an open-access article, first published in the JOURNAL OF ORAL \& MAXILLOFACIAL RESEARCH, distributed under the terms of the Creative Commons Attribution-Noncommercial-No Derivative Works 3.0 Unported License, which permits unrestricted non-commercial use, distribution, and reproduction in any medium, provided the original work and is properly cited. The copyright, license information and link to the original publication on (http://www.ejomr.org/) must be included. 